\title{
A CERÂMICA DE FIGURAS NEGRAS NO MEDITERRÂNEO: GRÉCIA DO LESTE NO NORTE DO EGEU - A RECEPÇÃO EM TASOS
}

Juliana Figueira da Hora*

Recebido em: 04/04/2019

Aprovado em: 25/07/2019

RESUMO: A cerâmica, como todos os produtos materiais da atividade humana, é utilizada e produzida em um contexto social. Os indivíduos aprendem técnicas de produção de cerâmica com os pais, outros parentes ou com mestres e tendem a reproduzir, em maior ou menor grau, as técnicas de produção dos que lhes ensinam. Nosso objetivo neste artigo é apresentar a dinâmica dos diálogos e aprendizagem de técnicas e estilos que circularam pelo Norte do Egeu, mais especificamente em Tasos, uma cidade fundada por Paros, no século VII a.C. Discorreremos sobre a trajetória das influências que perpassam a Ática e o Peloponeso na cerâmica de figuras negras como documento arqueológico no Mediterrâneo, mais especificamente na Grécia oriental. A recepção dos elementos da Grécia do Leste em Tasos foi bastante intensa no período arcaico, com a inserção das técnicas de figuras negras advindas de diversos locais do Mediterrâneo. As peculiaridades dos ateliês arcaicos do Norte do Egeu e os diálogos com regiões orientais trouxeram elementos representativos, técnicas e estilo recebidos por pintores locais e emulados nos ateliês arcaicos da ilha.

PALAVRAS-CHAVE: Cerâmica; Mediterrâneo; Tasos; Grécia do Leste.

THE BLACK-FIGURE POTTERY IN THE MEDITERRANEAN: EAST GREEK POTTERY IN THE NORTH OF AEGEAN RECEPTION IN THASOS

ABSTRACT: Like all material produced by human activity, the ceramics are used and produced in a social context. Individuals learn techniques of pottery production with parents, other relatives or masters, and tend to reproduce, to a greater or lesser extent, the production techniques of those who teach them. Our aim in this article is to present the dynamics of the dialogues and learning of techniques and styles that circulated around the North Aegean, more specifically in Thasos, a city founded by
* Doutora em Arqueologia pelo Museu de Arqueologia e Etnologia, Universidade de São Paulo. Pósdoutoranda do MAE, Universidade de São Paulo. juliusp10@gmail.com 
Paros in the VII century BC. We will talk about the trajectory of the influences that pass through Attica and the Peloponnese in the pottery of black figures as an archaeological document in the Mediterranean, more specifically in eastern Greece. The reception of the elements of Eastern Greece in Thasos was quite intense in the archaic period with the insertion of the techniques of black figures from various places in the Mediterranean. The peculiarities of the archaic workshops of the North Aegean and the dialogues with Eastern regions brought representative elements, techniques and style received by local painters and emulated in the archaic workshops of the island.

KEYWORDS: Ceramic; Mediterranean; Thasos; Eastern Greece.

\section{A CERÂMiCA COMO ObJETO DE ESTUdo: A IMPORTÂNCIA DA CONTEXTUALIZAÇÃo}

Trâmicas são produzidas para atender demandas, exigências locais que consideram determinados atributos como uma escolha que marca um "modo de fazer" próprio, como produto de uma construção das práticas sociais do contexto e que expressam aceitações e rejeições, as quais vão contribuir para a continuidade histórica de particularidades que perdurarão no tempo. Ao longo das duas últimas décadas, uma série de antropólogos culturais e arqueólogos considerou os estudos em contextos sociais imprescindíveis para a formação de quadros teóricos gerais (Sinopoli, 1991, p. 119). A apreensão dos papéis simbólico, social e econômico que envolve o "saber fazer" vasos por seus oleiros e/ou pintores implica a compreensão de seu uso em sociedade.

Ao escolher a cerâmica como objeto de estudo principal, devem ser levadas em conta, segundo Knappett e Malafouris (2010), duas características importantes: por um lado, deve-se levar em consideração o seu caráter pragmático, ou seja, trata-se de uma categoria de achado das mais abundantes em registros arqueológicos; e, por outro lado, a cerâmica é considerada a chave da cultura material humana, levando-nos aos caminhos da interpretação econômica, tecnológica e evolutiva de uma sociedade (Knappett; Malafouris, 2010, p. 588). Segundo Gordon Childe, a cerâmica é um objeto resiliente, pois é uma criação irreversível da junção do antiplástico com a argila, tornando-se uma forma perpétua nos tempos, imprimindo marcas de mudança, trajetos e tecnologia (Childe, 1936 apud Gamble, 2007, p. 10-37).

Knappett e Malafouris alertam para a necessidade de enfatizar que o vaso não é somente um recipiente que tem capacidade física para conter líquidos ou sólidos, mas também devem ser necessariamente consideradas as suas propriedades interativas, a agência e o uso (Knappett; Malafouris, 2010 passim). Os objetos pertencem, de fato, a um mundo sem fala, ao mesmo tempo em que estão inseridos em um mundo de significados e comunicação onde a ação foi impressa na materialidade.

As características primordiais de um objeto estão imersas na sua materialidade, ou seja, na sua forma, cor e dimensão, e elas, em seguida, adquirem função, transmitem significado. De acordo com Michel Bats, o artefato é polissêmico, já que o sujeito (produtor e consumidor) construiu e reconstruiu o seu significado. Além disso, uma mudança de contexto pode alterar a sua natureza. Bats vai além, ao dizer que objetos (artefatos) poderiam ser apreendidos e utilizados conscientemente e deixar, por exemplo, indícios emblemáticos de fronteiras, tais como de língua ou de religião (Bats, 2010, p. 9). 


\section{A CERÂmica no MEditerRÂNEO COMO DOCUMENTo}

Para Haiganuch Sarian (1996), é preciso que a cerâmica mediterrânica seja, de fato, transformada em documento e, para isso, é necessário inseri-la no campo epistemológico da "Arqueologia como Arqueologia, não como História ou como Antropologia" (Sarian, 1996, p. 37). A linguagem da cerâmica como objeto material possui uma natureza muito particular, uma linguagem própria, que a transforma em documento, e é o arqueólogo quem está preparado para decifrá-la, para dar voz àquele artefato em contexto embebido de significado, pois a metodologia própria, o saber arqueológico específico, o seu logos, é único (Sarian, 1996, p. 37).

Os maiores museus arqueológicos mundiais possuem ricos acervos de vasos gregos e o bom estado de conservação desses objetos deve-se não somente à habilidade e zelo dos restauradores, mas ao contexto onde foram encontrados, pois a maior parte dos vasos pintados foi retirada quase inteira de túmulos da Etrúria e do sul da Itália.

A partir de meados do século XVIII, com o enriquecimento das valiosas coleções de arte, os vasos foram estudados sob o viés estético pela primeira vez. No entanto, desde o início do século XIX, a atenção para o vaso como tal foi gradualmente perdendo importância, enfatizando-se o interesse pelas imagens, sob o ponto de vista iconográfico, especialmente a partir do momento em que, nos anos 1828-30, foram descobertos vasos pintados em Vulci (Sheibler, 2004, p. 14). A segunda metade do século XIX viu as grandes escavações terem início na Grécia. Os inúmeros vasos desenterrados promoveram uma importante ampliação de seus estudos, culminando, entre outras coisas, em datações cada vez melhor estabelecidas para a Grécia.

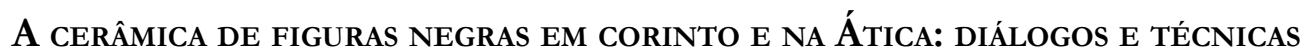

A técnica de figuras negras foi inventada em Corinto, e dominou o mercado de cerâmica do período arcaico, na primeira metade de 700 a.C. (Dias, 2009, p. 15). De acordo com Pomeroy (1999), os coríntios se especializaram em pequenos frascos decorados. A técnica consistia em pintura em silhueta negra com detalhes incisos. Após a queima, o detalhe pintado adquiria a cor do verniz negro brilhante (Pomeroy et al., 2004, p. 78). Corinto produziu o estilo orientalizante já no século VIII a.C., marcando uma passagem do tardogeométrico ao protocoríntio, desenvolvendo um estilo de inspiração oriental, com a posterior aplicação de nova técnica de figuras negras, adaptando o uso característico das incisões advindas do Oriente (Boardman, 1988, p. 10).

A cerâmica das oficinas áticas de figuras negras teve o seu início em meados de 630 a.C. e continuou até o final do século $\mathrm{V}$ a.C, quando as influências coríntias foram gradualmente abandonadas (Alexandridou, 2011, p. 1). Os pintores de vasos atenienses do final do século VII a.C. alcançaram grandeza de escala aliada a um maior controle e precisão na técnica. Os vasos áticos foram adquirindo incisões, adição de tinta vermelha e branca para detalhes, ao modo coríntio. A partir do último quartel do século VII a.C., os pintores atenienses começaram a se destacar com as figuras negras em seus trabalhos (Boardman, 1995, p. 14). 
O estilo decorativo que prevaleceu nos vasos de figuras negras áticas e coríntias foi o friso animal. No entanto, ambas as escolas, ao longo das duas primeiras gerações, começaram a aumentar o repertório da decoração, inserindo narrativas mais complexas, introduzindo novas formas e variações, tanto decorativas quanto formais. Os pintores pioneiros de vasos de figuras negras atenienses estavam muito arraigados ao orientalismo do estilo proto-ático. O "Pintor de Berlim" (anteriormente conhecido como mulher pintora) possui dois vasos atribuídos a ele encontrados na ilha de Egina. Esse pintor representava rostos humanos na decoração, preenchimento de fundo orientalizante em ziguezagues e rosetas pontuadas, e está cronologicamente inserido no período arcaico, no século VII a.C., momento de transição do protocoríntio para o protoático (Boardman, 1995, p. 15).

O Pintor de Nesso, ainda no século VII a.C., cujos vasos áticos representavam Górgonas e a figura de Héracles em vários momentos (por exemplo, em luta contra Nesso), utilizou ornamentos parecidos com o estilo protocoríntio do Pintor de Berlim. O nome "Nesso" deveu-se à predileção pela temática representativa de Héracles contra o centauro. No entanto, igualmente fez uso de um novo tratamento decorativo secundário, com as rosetas incisas, que se tornaram um traço ático importante ao longo do tempo. Seus vasos são grandes e as suas formas, monumentais, como, por exemplo, as crateras encontradas em Vari, na Ática. Outras formas importantes atribuídas ao Pintor de Nesso foram as ânforas de pescoço grande e uma nova invenção do oleiro ateniense, a "ânfora pançuda", e havia pequenos vasos, como lêcanas com decoração animal e gorgónea. O pintor utilizou incisões ou linhas duplas, que acentuavam características importantes dos animais coríntios (isto é, animais de inspiração oriental). Outros pintores atenienses contemporâneos ao Pintor de Nesso são: o Pintor do Pireu, Pintor de Belerofonte e Pintor de Leões, precursor de um padrão de fileiras de animais nos dois sentidos, horário e anti-horário (Boardman, 1995, p. 16).

Já no século VI a.C., mudanças consideráveis ocorreram nas várias formas de vaso e surgiram novos padrões de decoração. Pela primeira vez, os vasos atenienses começaram a competir nos mercados do mundo mediterrânico, sendo encontrados do Mar Negro à Líbia e da Espanha à Síria. Os representantes dessa nova fase são o Pintor de Górgona (600-580 a.C.), o Pintor do Cerâmico, o artista do grupo comastes e Sófilo.

O Pintor de Górgona, considerado o sucessor do Pintor de Nesso, economiza nas cenas mitológicas e figuras humanas para se dedicar mais aos frisos animais. O Pintor do Cerâmico - Keramikós - tem um estilo mais simples na adoção do friso animal do que o seu contemporâneo, adotando poucos detalhamentos na decoração (Boardman, 1995, p. 17).

De acordo com a classificação de Beazley, há ainda dois pintores que se destacam, chamados por ele de pintores KX e KY. Sophilos (de 580 a.C. a 570 a.C.), o último dessa geração, assinou quatro vasos: três como pintor e um como oleiro. No seu repertório de formas de vaso encontram-se grandes ânforas e dinos. Seu estilo, segundo Boardman, era "ambicioso" (Boardman, 1995, p. 18-19). 


\section{A RECEPÇ̃̃o dAS Figuras NEGRAS NA GRÉCIA ORIENTAL}

Os gregos do Oriente, na Antiguidade, segundo Cook e Dupont (1998), eram os chamados eólios (ao norte), jônios (na parte central) e dórios (ao sul, na região da Cária e Rodes). De acordo com a historiografia, a migração e fundação de cidades iniciou-se no final do século XI a.C. e pode ter continuado por cem anos ou mais (Cook; Dupont, 2008, p. i.). Abaixo, na Fig. 1, apresentamos o mapa com as cidades que fazem parte da Grécia Oriental.

FIGURA 1 - Mapa do Egeu e região da Grécia Oriental. Legenda numerada das cidades

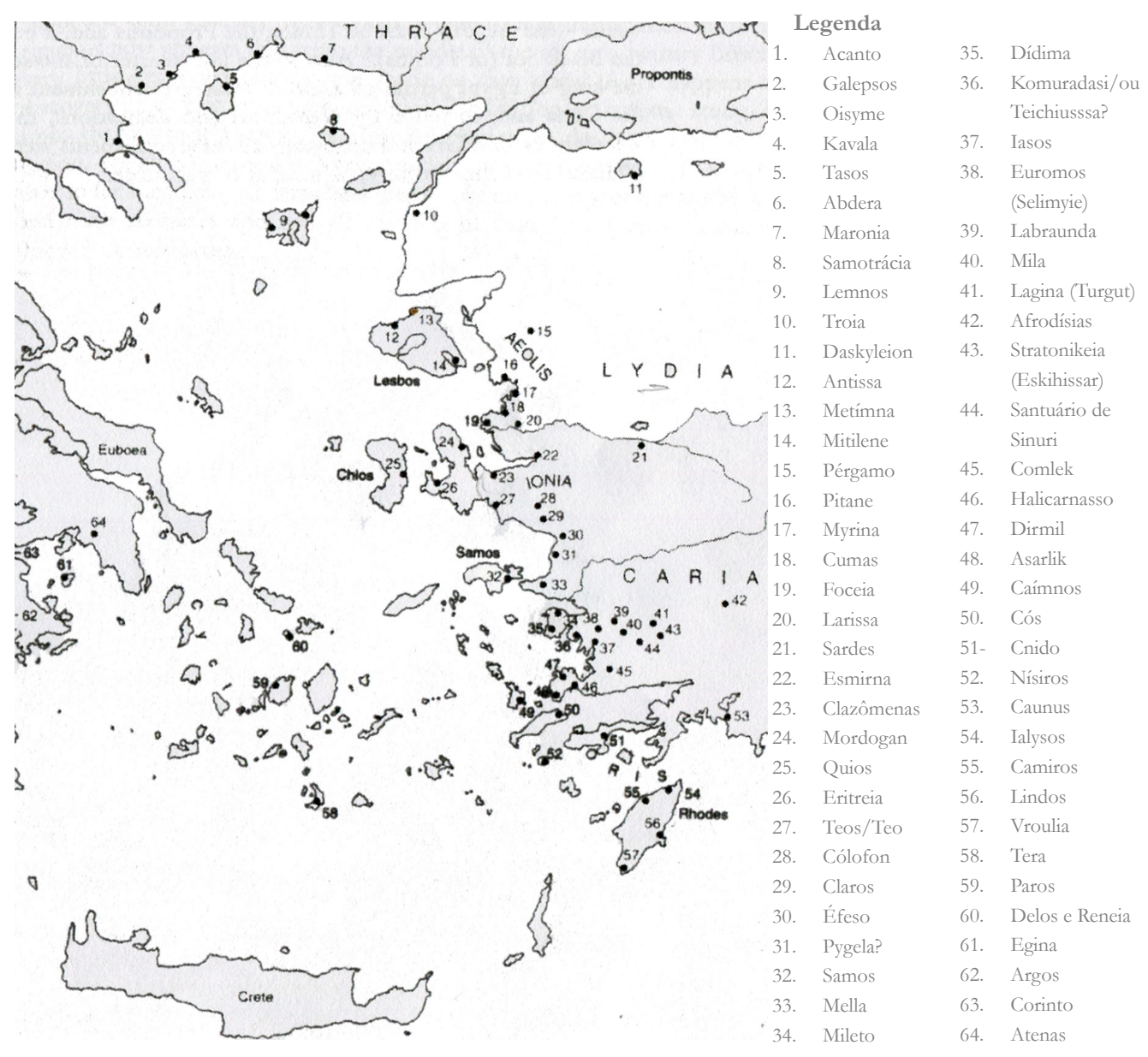

Fonte: Cook; Dupont, 2008, p. 3.

No que diz respeito à cerâmica decorada da Grécia Oriental, os primeiros achados ocorreram em Rodes. Já na pequena ilha de Nísiros, algumas sepulturas do século VI a.C. foram encontradas e publicadas, assim como um grande cemitério em Cós, que abrange o 
período protogeométrico e o geométrico (Morricone, 1982). Em Samos, nas escavações do importante santuário de Hera, foram encontradas muitas cerâmicas do protogeométrico da Grécia Oriental e algumas delas estavam em depósitos fechados. Em Empório, a sul de Quios, foram encontrados dois pequenos santuários com estratigrafias bem definidas e publicadas, sendo o mais importante localizado em Phanai. Este, porém, está apenas sumariamente relatado (em relatórios de escavação não publicados); o outro, com sepulturas parcialmente publicadas, localiza-se em Rizari, ao lado da cidade antiga - e moderna (Lemos, 1991). Em Lesbos, a cerâmica de Antissa foi sumariamente relatada e sobre Mitilene há, ainda, poucos dados publicados.

Veremos mais adiante que a circulação da cerâmica de estilo orientalizante foi uma das mais importantes influências para o Norte do Egeu e para Tasos do período arcaico. No próximo tópico, faremos uma breve introdução à cerâmica "wild goat style", que também foi muito influente na Grécia Oriental, fundindo-se com o estilo orientalizante e marcando uma mescla nos estilos.

\section{ESTILO ORIENTALIZANTE E O WILD GOAT STYLE OU "ESTILO CABRA SELVAGEM"}

De acordo com Cook e Dupont (1998, p. 29), o estilo orientalizante foi difundido em 680 a.C. Para Cook (1992), a qualificação dada ao estilo orientalizante surgiu a partir do uso de formas animais e humanas, representadas de maneira naturalizada e desenhadas, ao invés do uso da silhueta. Corinto, no século VIII a.C. (aproximadamente no ano de 720 a.C.), foi a primeira cidade grega a adotar e a desenvolver o estilo. Em Atenas, nas Cíclades e em Creta, a mudança começou por volta de 700 a.C. (Cook, 1992, p. 43). A decoração animal possui uma fauna em comum: leão, touro, javali, esfinge, grifo, cabra, veado, cachorro, lebre, águia, galo e ganso, sendo que as cabras e os veados já eram conhecidos no Geométrico. $\mathrm{Na}$ segunda metade do século VII a.C., novas espécies se tornaram populares. Corinto parece ter recebido novas influências, pois a pantera, o leão e vários animais híbridos eram representados com maior frequência (Cook, 1992, p. 42).

Ao mesmo tempo, os motivos típicos do estilo geométrico se tornaram menos rígidos e os detalhes, mais "naturalizados", com forma humana ou animal. Os artesãos, influenciados pelo estilo oriental, usaram incisões para dar mais detalhes aos seus desenhos - uma técnica já utilizada para peças de bronze e marfim. Os destaques em vermelho e branco e os tons de marrom e preto muitas vezes dão uma impressão real de policromia contra a superfície pálida do engobo. Os vasos são muitas vezes pintados em um estilo miniaturista, sendo sua superfície dividida em zonas, cada uma com um tipo diferente de decoração, enquanto o fundo é ornamentado com pontos em padrões de roseta. Os frisos de animais e de cenas de caça pitorescas também são uma indicação da influência oriental. O estilo cabra selvagem, ou Wild Goat Style, se desenvolveu com maior ênfase na Grécia oriental e no Egito, mas, como podemos observar na Fig. 1, o alcance foi amplo: desde a Ática, passando pela Trácia e alcançando até as ilhas do sul, próximas à Rodes. Esse notável estilo ornamentado se espalhou por toda a costa jônica da Ásia Menor e pelas ilhas gregas 
(Rodes, Quios, Clazômenas e Náucratis) no decurso do século VII a.C. até os primeiros anos do século VI a.C. (Martine, 1994, p. 24). Na Fig. 2, podemos observar uma enócoa trilobada de Corinto, em que a influência orientalizante se mistura com o "Wild Goat Style".

FIGURA 2 - Enócoa coríntia orientalizante influenciada pelo "Wild Goat Style” (625 a.C.).

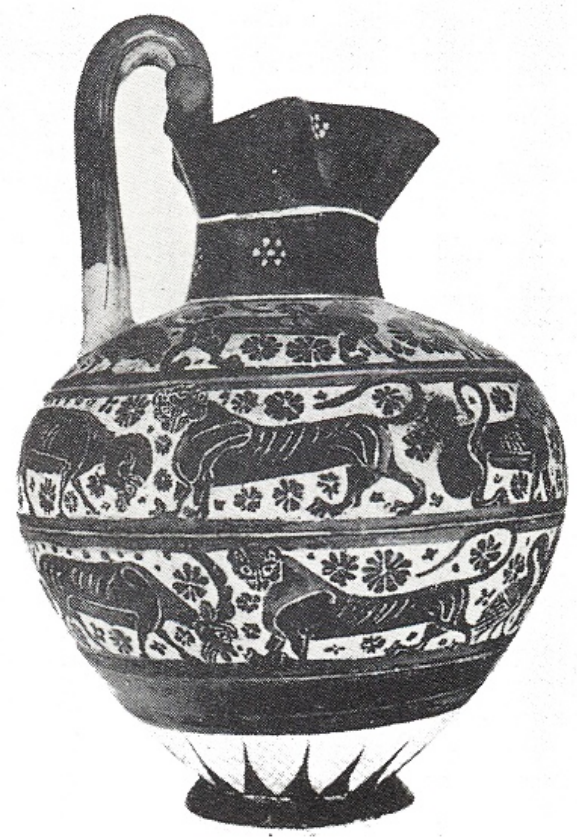

Fonte: Cook, 1992, prancha 11 B.

De acordo com Brown (1989), “cabra selvagem”, é uma expressão moderna que descreve a pintura em vaso produzido na Grécia Oriental, ou seja, nas ilhas jônicas de norte a sul, entre c. 650 a 550 a.C. O estilo deve seu nome aos motivos predominantes encontrados em tais vasos: os frisos de cabras. No entanto, como dito antes, esses animais não são as únicas criaturas neles representadas. Outros animais, como lebres, leões, cães, grifos e esfinges, também podem ser encontrados junto às decorações ditas de "preenchimento", no caso, os florais, símbolos, meandros, entre outros (Brown, 1989).

O estilo "cabra selvagem" emergiu do estilo orientalizante e dominou a decoração de cerâmica da Grécia Oriental por pelo menos cem anos. Foi considerado erroneamente originado de Rodes, pois nessa ilha foram encontrados vasos com decoração típica do estilo em grande quantidade. Outras publicações nomeavam-nas como cerâmicas rodiomilésias e/ou milésias. A cerâmica designada Wild Goat Style é classificada, atualmente, como uma especificidade orientalizante da Grécia Oriental (Cook; Dupont, 2008, p. 32).

Em um primeiro momento, as semelhanças com modelos sírios ou fenícios ainda eram marcantes. Em 650 a.C., no sul da Jônia, o estilo “cabra selvagem” estava em sua primeira 
fase; as formas ainda eram do subgeométrico e a decoração foi marcada pela representação de cães, leões, esfinges e grifos (Cook; Dupont, 2008, p. 32). Os primeiros exemplares do estilo começam a aparecer, de maneira mais consolidada, a partir do chamado Middle Wild Goat Style I (640-630 a.C.), de acordo com Cook e Dupont (1998). As características decorativas são marcadas pelos florais representando flores de lótus, palmetas, rosetas e detalhes mais apurados da fauna. Com a crescente adoção do estilo orientalizante na Grécia Oriental, o chamado Middle Wild Goat Style II (625-615 a.C.), cf. Fig. 3., apresenta posteriormente uma decoração e formas mais variadas, marcadas pelas aves e por criaturas monstruosas híbridas para o repertório de imagens (Cook; Dupont, 2008, p. 40).

FIGURA 3 - À esquerda: Enócoa (630 a.C.) do Middle Wild Goat Style I.

À direita: Enócoa (625 a.C.) Middle Wild Goat Style II
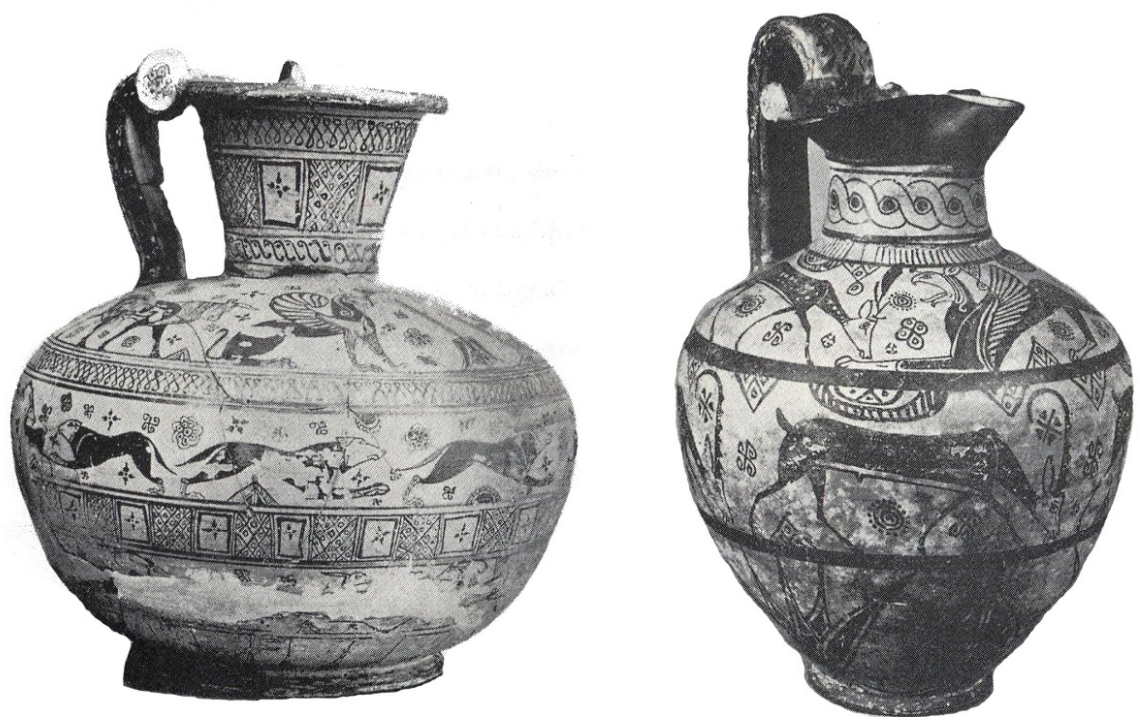

Fonte: Cook, 1992, Prancha 30 A e B.

\section{Quios, PRINCIPAL RECEPTORA Do ESTILO “CABRA SELVAGEM”}

O primeiro grande achado de cerâmica arcaica no estilo "cabra selvagem" de Quios foi em Náucrates, no Egito, em meados da década de 1880, nomeado erroneamente como de procedência local. Cerca de trinta anos depois, com as escavações em Kato Phana (Phanai), em Quios, os achados de Náucrates começaram a ser questionados, pois ali foram encontradas cerâmicas semelhantes (Cook; Dupont, 2008, p. 46). A cerâmica de Quios é a melhor compreendida das escolas gregas orientais de seu tempo. Seus vasos são geralmente fáceis de reconhecer pela brancura do engobo, o mais branco no século VI. a.C., pelo uso de cobertura interna em vasos abertos e pela cor rosada da argila. A datação das cerâmicas arcaicas de Quios do século VI a.C. é assegurada pelas publicações de material arqueológico 
de Empório (Quios), de Tocra (na Líbia) e de alguns contextos de túmulos de Esmirna (Cook, 1992, p. 141). Em Quios, o estilo orientalizante foi adotado concomitantemente ao estilo "cabra selvagem", no século VII a.C., na transição do Middle Goat Style I e Middle Goat Style II (Cook; Dupont, 2008, p. 46; cf. Fig. 4).

FIGURA 4 - Fragmento de prato de Quios, “Wild Goat Style IP” (615 a.C.)

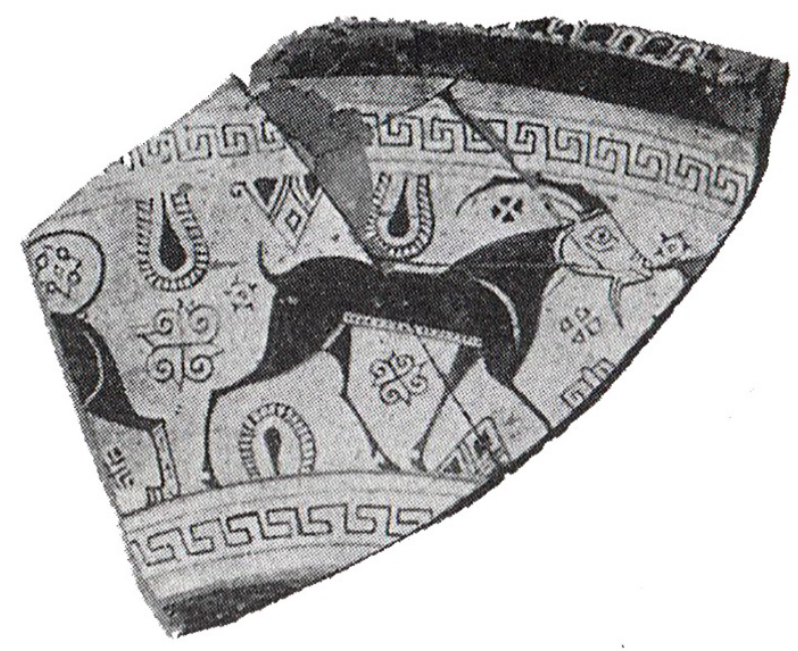

Fonte: Cook, 1992, Pr. 31 C.

\section{Tasos e a recepção cultural: a Cerâmica de figuras negras tasienses E O ECLETISMO}

A região do Norte do Egeu era um cenário para lendas que circulavam no sul da Grécia continental e nas ilhas do sul do Mar Egeu. As riquezas da região levaram à saída de expedições fundadoras das ilhas Cíclades em busca de novos assentamentos, por um lado para se enriquecerem e, por outro, para resolverem seus problemas demográficos e urbanos. A fundação da pólis de Tasos por Paros é um desses casos típicos (Fig. 1). O líder da fundação foi Telesicles, pai do poeta lírico Arquíloco que, uma geração mais tarde, aproximadamente em 650 a.C., veio a Tasos acompanhado de seu amigo, o general Glauco, e de alguns novos colonos, que partiram para conquistar a costa da Trácia. Durante essas guerras de conquista, Glauco foi morto e o seu cenotáfio foi escavado em 1914 na ágora de Tasos (Lazaridis, 2003, p. 14).

Sara Owen (2003) nos apresenta, no artigo "Of dogs and men: Archilochos, Archaeology and the Greek settlement of Thasos”, relatos literários feitos por Arquíloco. 
O filho do oikista ${ }^{1}$ Telesicles se estabeleceu na ilha de Tasos durante a fundação grega. De acordo com os relatos, Arquíloco possuía aversão aos trácios, chamava-os de "miseráveis", escória da Grécia. Desdenhava da ilha dizendo que se parecia com o "traseiro de um asno" e que não era bonita como Síbaris, na Itália, e descrevia os trácios como "cães" (Owen, 2003, p. 1).

A ilha abriu o fluxo comercial tanto no nordeste do Egeu quanto no continente próximo. Heródoto, no livro VI, ao descrever as Guerras Médicas, ocorridas no século V a.C., conta que havia minas de ouro localizadas entre Cenira e uma região denominada Enira e recorda que os primeiros a explorarem essas minas tasienses foram os fenícios (VI, 46-47).

Tive ocasião de ver essas minas. As mais notáveis de todas eram as descobertas pelos Fenícios que povoaram com Tasos essa ilha, a que este último deu o seu nome. Estão situadas entre Cenira e uma localidade denominada Enira. Diante da ilha de Samotrácia ergue-se uma grande montanha semidestruída pelas escavações precedentes.

(História, VI, 46-47)

Tasos continuou prosperando e seus santuários foram preenchidos por monumentos e oferendas (Grandjean; Salviat, 2000, p. 8). A nova pólis relacionava-se comercial e culturalmente com outras póleis e outros povos. Os vestígios arqueológicos mostram uma grande influência externa na cerâmica, no bronze e no marfim, ilustrando a relação com as Cíclades e com os ródios, jônios, coríntios e atenienses no século VI a.C. Poderíamos atribuir este crescimento à história política de Tasos? Sabemos que, do início do século VI a.C. até 540 a.C., Tasos viveu sob um regime tirânico, passando por um período oligárquico moderado de 540 a 465 a.C. até tornar-se dependente de Atenas. Considere-se que, neste ínterim - início do século $\mathrm{V}$ a.C., mais precisamente em 492 a.C. -, os tasienses se submetem ao rei persa Dario, agora com domínio da Jônia (Heródoto, VI, 44). Em 491 a.C., quando Dario e seu general Mardônio invadiram a Trácia, eles forçaram Tasos a desmantelar suas muralhas e pagar tributo. Em 477 a.C. Tasos adere à liga de Delos, um momento em que Atenas é dominante no Mar Egeu e as importações áticas estão bastante ativas (Grandjean; Salviat, 2000, p. 28).

Em meados do século $\mathrm{V}$ a.C., há dispersão de moedas de prata, o que mostra a amplitude das relações comerciais. No final do período arcaico e início do período clássico, a cidade estava rica, com um aparato urbano bastante estruturado. Na necrópole, as escavações forneceram material cerâmico fragmentado.

\footnotetext{
${ }^{1}$ Oikista, em grego oikistés: "Na Grécia Antiga, o fundador de uma apoikia (uma nova cidade); o arquegueta como Apolo". O oikista era enterrado com honras de herói "na ágora e recebia, anualmente, culto heroico" (LABECA, acesso em jan. 2019).
} 


\section{TASOS E AS INFLUÊNCIAS ÁTICAS E CORÍNTIAS}

Tasos importou, durante o século VI a.C, e em abundância no século V a.C., lêcanas de figuras negras áticas, que foram fonte de inspiração para as formas dominantes no ateliê de figuras negras tasienses. A adoção de uma decoração de influência ática é bastante marcada nos florais, nas composições simétricas, na ampliação do repertório animal, principalmente com o grupo dos cisnes, além das representações humanas (Coulié, 2002, p. 174).

A influência coríntia nos vasos tasienses é notada por L. Ghali-Kahil: "Este estilo com figuras negras é fortemente inspirado pela cerâmica coríntia” (Ghali-Kahil, 1960, p. 52). Anne Coulié discorda da afirmação, já que, em sua opinião, seria muito difícil identificar empréstimos específicos. Segundo ela, o estilo animal e, ainda mais obviamente, as figuras humanas que decoram esses vasos deveriam pouco a Corinto. As influências mais fortes teriam vindo dos ateliês de Quios e da Jônia do Norte. No entanto, essa pesquisadora lembra que esses dois locais também adotaram uma decoração inspirada nos ateliês coríntios (Coulié, 2002, p. 175). Ainda assim, não haveria como confirmar uma influência direta dos ateliês coríntios em Tasos, já que a recepção dos mesmos se dá a partir da importação dos vasos produzidos na Grécia Oriental (Coulié, 2000, p. 113-15).

Como explicar então o fato de que Corinto não desempenhou o papel de modelo privilegiado, como foi o caso das figuras áticas negras do início do século VI a.C., em Tasos? Ora, provavelmente isso se deve às influências da Grécia Oriental, cuja recepção teve como proveniência principal Quios, o Norte da Jônia e a Trôade, como veremos a seguir. $\mathrm{O}$ fator geográfico favoreceu os contatos com a região do Norte do Egeu. No caso das influências áticas, de acordo com Anne Coulié (2002), elas foram facilitadas pelo impacto das abundantes exportações de Atenas durante os séculos VI e V a.C., o que não se verificou com tanta intensidade em Corinto (Laffineur, 1986, p. 27).

\section{TAsos E A RECEPÇão do ESTILO “CABRA SELVAGEM": INFLUÊNCIA DE QUIOS, NORTE DA JÔNIA E TRÔADE}

O ateliê de Tasos, de acordo com Cook e Dupont, possuía pintores atentos e inventivos que estavam fazendo suas próprias versões de figuras negras, a partir das influências principalmente de Quios e da Ática. O Wild Goat Style que influenciou as decorações em Tasos se assemelha ao que se pode identificar no Wild Goat Style Middle II ou "Late Goat Style", advindos de Quios, do norte da Jônia e da Trôade (Cook; Dupont, 1998, p. 68).

\section{Quios}

O estabelecimento de relações estreitas entre as duas cidades é atestado pelas importações de cerâmicas dos ateliês de Quios. Os modelos de vasos e de decorações são bastante presentes nas emulações em Tasos. A adoção dos padrões animais do estilo "cabra selvagem" diretamente de Quios ocorreram no final do século VII a.C., por meio das influências advindas dos cálices com representações de animais, e se prolongaram no 
século VI a.C.; e do ateliê de "Esfinge e Leão", ativo durante a primeira metade do sexto século, que em Tasos foi muito presente como modelo.

\section{Jônia setentrional}

Entende-se por Jônia Setentrional, como podemos observar no mapa (Fig. 1), a região que compreende a parte Oeste de Clazômenas e Eritreia. Foram identificados dois ateliês em Clazômenas que marcam mais especificamente o estilo "cabra selvagem” na região (Cook; Dupont, 2008, p. 52).

A cerâmica da Jônia Setentrional é um modelo persistente em Tasos, desde o final da produção orientalizante local, marcada pelas produções do Pintor de Tradição² (Walter, 1968, p. 80-81). As formas de pratos e enócoas importadas de Clazômenas explicam a precisão de empréstimos dessas formas usuais em Tasos. Anne Coulié nos fornece a informação de que em escavações recentes de Esmira, região a norte de Clazômenas, foram descobertas lêcanas monumentais decoradas com imagens de mulheres, ainda não publicadas pelo arqueólogo G. Bakir (Coulié, 2002, p. 172).

\section{Trôade}

A Trôade é uma antiga região a noroeste da Anatólia (Fig. 1). A Trôade, mais

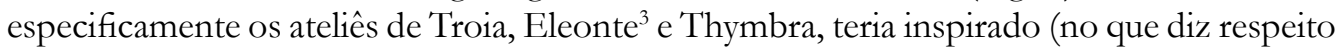
aos traços decorativos) os pintores de Tasos. Foram encontradas, no Artemísion de Tasos, formas de vasos de Eleonte, a chamada côtila, não adotada nos ateliês de Tasos (Coulié, 1996, Pl. LX).

\section{FIgURAS NEGRAS TASIENSES: UM ATELIÊ LOCAL}

A cerâmica de figuras negras tasienses constitui um material privilegiado de estudos de um estilo local. ${ }^{4} \mathrm{~A}$ forte tradição do ateliê remonta à época orientalizante e se prolongou por alguns séculos. Para Ghali-Kahil é possível designar como "tasiense” esta inovação, por meio da recepção de elementos decorativos na cerâmica e também por meio da durabilidade das características locais, sendo influenciadas por modelos cicládicos, coríntios e áticos em figuras negras (Salviat, 1978). A questão da imitação e adaptação de modelos áticos também é reforçada por Weill (1959). Para Anne Coulié (2002), a noção de “imitação” deve ser aprofundada na historiografia, para que possamos compreender particularmente o fenômeno

\footnotetext{
${ }^{2}$ O Pintor de Tradição é a designação atual de um dos pintores de cerâmica de figuras negras em Tasos. Foram atribuídos a ele 27 vasos do conjunto de 413 vasos catalogados.

${ }^{3}$ De acordo com Boardman (1988, p. 265), há a hipótese de que haveria uma oficina ateniense em Eleonte. ${ }^{4}$ Anne Coulié (2002, p. 167) recusa o emprego abusivo de "estilo" para a expressão em figuras negras. Para a pesquisadora, "figuras negras" classifica-se como técnica. Já "estilo" reúne diversos atributos materiais, de diversas naturezas. Tudo na descrição das funções de objetos como um marcador cultural será considerado um ato de estilo.
} 
tasiense de apropriação de estilos. Para Brommer (1951), o processo de produção artística e artesanal desde a época arcaica no mundo mediterrânico não se configura como um processo imitativo. $\mathrm{Na}$ ceramologia, o fenômeno das réplicas, isto é, duplicatas exatas, raramente é documentado (Brommer, 1951 passim).

\section{Figuras NEgRAS TASIENSES E AS SUAS ESPECIFICIDADES}

\section{Ateliê de figuras negras tasienses}

Embora não se tenha encontrado no registro arqueológico das oficinas de produção de figuras negras tasienses em Limenas, a existência de produção local é afirmada e defendida desde os anos 1960 para Tasos (Ghali-Kahil, 1960, p. 35). Esse ateliê, após 550 a.C., constituiuse como o núcleo dessa produção. Anteriormente, entre os séculos VII e VI a.C., houve uma fase oriental inspirada em modelos cicládicos da metrópole Paros. Para compreender a evolução desse ateliê, portanto, foi necessário compreender a proximidade com Quios e com outras regiões, como vimos acima. De fato, estilisticamente, essa cerâmica está muito próxima de Quios, mas a marca local está na utilização não sistemática do engobo e na aparição da lêcana como forma principal. Anna Lemos, pesquisadora de cerâmica de Quios, propõe a emigração do estilo de Quios para Tasos e a Macedônia setentrional (Lemos, 1991 apud Coulié, 2002, p. 184).

Para Anne Coulié (1998), é preciso restaurar a oficina, dimensioná-la nos termos da atribuição dada aos pintores, levando em consideração a contemporaneidade dos artesãos. A cronologia marcada pela técnica de figuras negras foi crucial como um marcador temporal importante, a partir do início do século VI a.C. O trabalho com a individualização dos pintores permite retomar a antiga definição de artesão como tekhnites. Essa categorização nos permite inserir os pintores ceramistas tasienses no seio social do processo, por meio de uma rede de empréstimos e afiliações que definem o processo de colaborações e aprendizagem dos artesãos (Coulié, 1998, p. 724). Para Philippe Bruneau, a troca de conhecimento acontecia de forma coletiva, em colaboração com muitos artistas, definindo mutuamente, em uma relação dialética de mesma realidade tangível, suas produções (Bruneau, 1975, p. 451 apud Coulié, 1998, p. 724).

Além do estilo, decoração e técnica, outra marca do ateliê tasiense está na forma da lêcana. Relativamente raras no mundo grego, em Tasos é a mais representativa da oficina. Sua longevidade de um século parece ter ultrapassado a produção ática, beócia e eubeia, locais que trouxeram os modelos de lêcana aos pintores tasienses (Lioutas, 1987, p. 44). Em Tasos, ela se apresenta com várias características peculiares: decoração da superfície de apoio do pé, frequência da apresentação de frisos figurativos invertidos raros, medalhões internos decorados, borda não implicando em uma colocação de tampa. 


\section{Ateliê de Tasos: pintores}

A reflexão sobre os ateliês de produção faz parte do processo de contextualização da cerâmica, em um nível complexo de identificação dos pintores e de ateliês locais. Anne Coulié argumenta que, por um lado, para os estudos do caso específico do ateliê tasiense de figuras negras, a metodologia atributiva pode parecer ultrapassada; por outro, permite traçar uma trajetória tradicional de determinados ateliês, inclusive a possibilidade de avaliar a dimensão produtiva dos mesmos, como bem vimos acima (Coulié, 1998, p. 719).

A oficina tasiense foi dividida por Anne Coulié (2002) em "gerações de pintores", designadas primeira, segunda, terceira e última geração de pintores tasienses. Na primeira geração, foram identificadas quatro mãos em 150 vasos": "Pintor de Tradição", "Pintor de Quios", "Pintor de Poseidon" e "Pintor de Grandes Pratos". Cronologicamente, esses pintores atuaram de 590 a 560 a.C. Na segunda geração, mais de 100 vasos foram atribuídos a dois pintores, que praticamente seguiram a tradição anterior, identificados: o "Pintor Fiel", que foi influenciado pelo "Pintor de Poseidon", da primeira geração, e o "Pintor de Troilo", que é um seguidor do "Pintor de Quios". A cronologia para a segunda geração vai de 560 a 525 a.C. A terceira geração foi identificada com um único pintor, o chamado "Pintor de Palestra". A inovação da cena figurada foi identificada em um conjunto de 60 vasos atribuídos a ele e a cronologia vai de 525 a 501 a.C. A quarta geração (também chamada de última geração por A. Coulié) de pintores seria a dos chamados "Pintores Anônimos", aos quais foram atribuídos mais de 80 vasos cuja cronologia dataria do final do século VI a.C. (Coulié, 2002, p. 7-163).

\section{CONSIDERAÇÕES FINAIS}

Este artigo mostrou que, para inserirmos a reflexão sobre a cerâmica produzida no Mediterrâneo no contexto mais amplo da sociedade grega, é necessário compreender como esses objetos se inserem no âmbito do desenvolvimento social, religioso, político e econômico no mundo arcaico grego (Stissi, 2002, p. 7).

Vimos, portanto, que a recepção, circulação e emulação de elementos gregos da Grécia Oriental é bastante evidente na cerâmica de figuras negras tasienses, um estudo de caso importante para a compreensão da ecleticidade das técnicas, a variedade de estilos que foram adotados nas oficinas de cerâmica de Tasos, onde os elementos decorativos chegaram por meio dos pintores e oleiros de outros locais da Grécia, trazendo inovações e características que, pela análise aprofundada da materialidade, configuram-se como um conjunto único e local de produção no Mediterrâneo. A cerâmica de figuras negras tasienses destaca-se pelas inovações locais, por meio das mãos identificadas de pintores/oleiros, atuantes na produção de um ateliê coerente em termos de reprodução da decoração ao longo das gerações do período que vai de 590 a.C. a 501 a.C. Estes fragmentos cerâmicos de figuras negras especificamente de Tasos, portanto, contam-nos uma parte das relações

\footnotetext{
${ }^{5}$ Os nomes dos pintores foram aportuguesados para este artigo.
} 
de intercâmbio entre estilos, técnica, povos, culturas e modus operandi de pintores e oleiros que trocaram conhecimento no período arcaico no Mediterrâneo e o emularam, a partir das diversas influências que marcaram a região nessa época.

\section{REFERÊNCIAS}

ALEXANDRIDOU, Alexandra. The Early Black-Figured Pottery of Attika in Context (c. 630-570 BCE). Leiden: Brill, 2011. (Monumenta Graeca et Romana, v. 17).

BATS, Michel. Les objets archéologiques peuvent-ils véhiculer une identité ethnique? TRÉZINY, H. (Ed.). Grecs et indigènes de la Catalogne à la Mer Noire: Actes des rencontres du programme européen Ramses 2 (2006-2008). Paris: Errance, 2010. p. 9-13.

BOARDMAN, John. Archaic Greek Gems. London: Thames \& Hudson, 1968.

BOARDMAN, John. Athenian Black Figures Vases: a Handbook. $2^{\text {nd }}$ ed. reimp. London: Thames and Hudson, 1995.

BROWN, Christopher. Aries, Aphrodite, and the Laughter of the Gods. Phoenix, v. 43, p. 283-93, 1989.

COOK, Robert Manuel. Greek painted pottery. London: Routledge, 1992.

COOK, Robert Manuel; DUPONT, Pierre. East Greek Pottery. London: Routledge, 1998.

COULIÉ, A. La Céramique Grecque Aux Époques Géométrique Et Orientalisante (XI-VI Siécle Av. J.-C.). Paris: Picard, 2013.

COULIÉ, A. La Céramique Thasienne à Figures Noires. Athènes; Paris: École française d'Athènes; De Boccard, 2002. (Études Thasiennes, 19).

COULIÉ, A. Réflexion sur la structure d'un atelier à partir de ses productions: les cas de l'atelier thasien à figure noires. Topoi, v. 8, n. 2, p. 719-729, 1998.

COULIÉ, A; BOUQUILLON, A. La céramique de la Grèce de l'est: le style des chèvres sawvages: la collection du Musée du Louvre. Paris: Gourcuff-Gradenigo, 2014.

DIAS, Carolina Kesser Barcelos. As abordagens metodológicas para o estudo de vasos gregos: a atribuição e a análise iconográfica. Revista Eletrônica Antiguidade Clássica, v. 4, p. 47-65, 2009.

FRANCISCO, Gilberto da Silva. Grafismos gregos: escrita e figuração na cerâmica ática do período arcaico (do século VII-VI a.C.). Revista do Museu de Arqueologia e Etnologia, suplemento 6, 2008.

GAMBLE, Clive. Origins and Revolutions: Human Identity in Earliest Prebistory. Cambridge: Cambridge University Press, 2007.

GHALI-KAHIL, L. La céramique grecque (fouilles 1911-1956). Athènes; Paris: École française d'Athènes; De Boccard, 1960. (Études Thasiennes, 7). 
GRANDJEAN, Y; SALVIAT, F. Guide de Thasos. Athènes: École Française d'Athènes, 2000. v. 3 .

HERÓDOTO. História. Primeiro relato clássico da guerra entre gregos e persas. Trad. J. Brito Broca. 2. ed. São Paulo: Ediouro, 2001.

HOZ, Javier de. Les écritures. In: ÉTIENNE, Roland (Org.). La méditerranée au VIIe siècle av. J.-C. Paris: De Boccard, 2010.

HORA, J. F. A cerâmica de figuras negras tasienses no contexto arqueológico: múltipla Ártemis e o feminino na Tasos arcaica. 2018. Tese (Doutorado em Arqueologia) - Museu de Arqueologia e Etnologia, Universidade de São Paulo, São Paulo, 2018. Dor: 10.11606/T.71.2018.tde-01102018-145437. Acesso em: 17 jul. 2019.

KNAPPET'T, Carl; MALAFOURIS, Lambros. Material agency: Towards a non-anthropocentric approach. Berlin: Springer, 2010.

LABECA. Glossário. São Paulo. Disponível em: http://labeca.mae.usp.br/pt-br/glossary/. Acesso em: 1 jan. 2019.

LAFFINEUR, R. Francis Croissant. Les protomés féminines archaïques. Recherches sur les représentations du visage dans la plastique grecque de 550 à 480 av. J.-C. L'Antiquité Classique, t. 55, p. 576-578, 1986.

LAZARIDIS, D. Amphipolis. Athens, Ministry of Culture: Archaeological Receipts Fund, 2003.

LEMOS, Anna. Archaic Pottery of Chios. The Decorated Styles. Vol. 1: text. Oxford: Oxford University Committee for Archaeology; Oxbow Books, 1991.

LIMA, A. C. C. O "espaço do fabuloso" e a representação de animais na cerâmica coríntia no século VII a. C. Revista Tempo, v. 21, n. 38, p. 1-17, 2015.

LIOUTAS, A. Attische schwarzfigurige Lekanai und Lekanides. Würzburg: K. Triltsch, 1987. (Beiträgezur Archäeologie, 18).

MORRICONE, L. Sepulture della Prima Età dell Ferro a Coo. Annuario dela Scuola Archeologica di Atene, 56 (1978), 1982, Serr. T. 28.1 (inv. No 1058).

OWEN, S. Of Dogs and Men: Archilochos, archaeology and the Greek settlement of Thasos. Proceedings of the Cambridge Philological Society, v. 49, p. 1-18, 2003.

PEREIRA FILHO, A. C. Anfora de Apolo: um estudo sobre cerâmica grega cicládica meliana do século VI a.C. 2011. Dissertação (Mestrado em Arqueologia). Museu de Arqueologia e Etnologia, Universidade de São Paulo, São Paulo, 2011. DOI: 10.11606/D.71.2012.tde-05062012-133937

POMEROY, Sarah. B. et al. A brief history of ancient Greece: politics, society, and culture. New York: Oxford University Press, 2004. 
PORTO, V. C.; HORA, J. F. da. Timbres nas ânforas de Tasos: circulação, produção e conexão no Mediterrâneo. Romanita - Revista de Estudos Grecolatinos, Vitória, v. 7, p. 170-187, 2016.

SALVIAT, F. La céramique de style chiote à Thasos. In: LES CERAMIQUES de la Grèce de l'Est et leur diffusion en Occident. Naples: Centre J. Bérard, 1978. p. 87-92. (CNRS Collection du Centre Jean Bérard, 4).

SARIAN, Haiganuch. Vasos Clássicos, ceramografia e ceramologia: algumas reflexões. Cerâmicas da Quinta da Boa Vista, Rio de Janeiro. Catálogo da Exposição, 16 nov. 1995 a 16 mar. 1996. Rio de Janeiro: Museu Nacional de Belas Artes, 1996. p. 31-38.

SINOPOLI, Carla. Approaches to Archaeological Ceramics. New York: Plenum Press, 1991.

STISSI, V. V. Pottery to the people. The production, distribution and consumption of decorated pottery in the Greek world in the Archaic period (650-480 BC). Studies, v. 2, p. 1-3, 2002.

WALTER, H. Frühe samische Gefässe des 6. Jahrhundersts v. Chr., Samos V, 1968. 